\title{
Effects of Teaching Efficacy of Early Childhood Teachers on the Peer Play Interactions of Young Children: Mediating Effects of Teacher-Child Interactions
}

\author{
Su Mi Lim ${ }^{1}$, Hae Shin Hwang ${ }^{2}$ \\ Ph. D. Student, Department of Family Welfare, Sangmyung University, Seoul, Korea ${ }^{1}$ \\ Professor, Department of Family Welfare, Sangmyung University, Seoul, Korea ${ }^{2}$

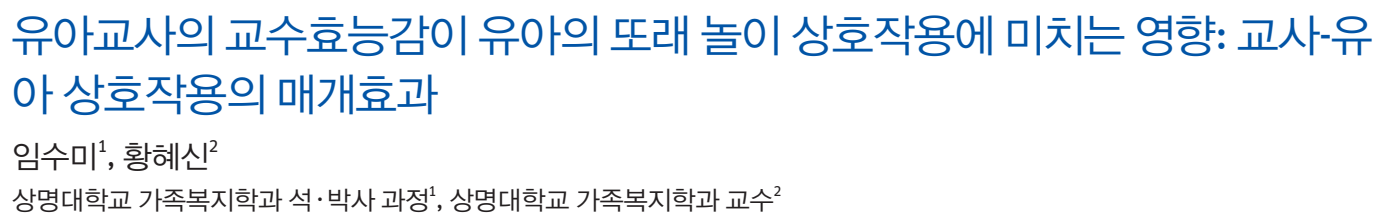

Objectives: This study aimed to examine the effects of teaching efficacy of early childhood teachers on the peer play interactions of young children, and verify the mediating effects of teacher-child interactions on this relation.

Methods: The study participants were 403 six-year-old children and 403 teachers in charge of young children in daycare centers in the 7th-year data of the Panel Study of Korea Children (PSKC). This study conducted descriptive statistics and correlation analysis using SPSS 25.0 for data analysis, and verified the mediating effects by using SPSS PROCESS macro.

Results: Teacher-child interactions completely mediated the relationship between the teaching efficacy of early childhood teachers and the play disconnection of young children.

Conclusion: The results of this study suggest the necessity of experiences that could connect the continuous provision of opportunities to support the interaction of early childhood teachers. This is achieved through the education of teachers, the early childhood teachers' active attempts of efficient interactions with young children, and the peer play interaction of young children. Especially, this emphasizes the role of early childhood teachers as an interactor who leads young children by instructing and scaffolding their play. However, this study verified that within the play-centered curriculum, the roles of teachers should be as a peer who learns with children, a play medium of daily life, and a play leader with young children as a play peer, which is more important.

Keywords: teaching efficacy, peer play interaction, teacher-child interaction, panel study of Korean children

\section{Introduction \\ 놀이는 유아에게 또래와 같이 일상 속에서 경험하는 즐거움을 \\ Corresponding Author: Hae Shin Hwang, Professor, Department of Family Welfare, Sangmyung University, 20, Hongjimun 2-gil, Jongno-gu, Seoul, Korea E-mail: hshwang@smu.ac.kr}

이끄는 가장 중요한 활동이다. 우리나라의 국가수준 누리과정 은 일과 속에서의 충분한 놀이의 중요성을 언급하고 놀이중심 교육과정을 운영하고 있으며, 2019년 개편된 놀이중심 누리

(C)The Korean Association of Child Studies

This is an Open Access article distributed under the terms of the Creative Commons Attribution Non-Commercial License (http:// creativecommons.org/licenses/by-nc/4.0) which permits unrestricted noncommercial use, distribution, and reproduction in any medium, provided the original work is properly cited. 
과정 개정안은 유아가 행복해지는 교육을 지지하고 유아의 놀 이와 상호작용을 강조하고 있다(Lim et al., 2019). 유아교육현 장에서 놀이중심 교육 실천이 강조되면서 유아가 놀이 속에서 또래와 성공적이며 긍정적인 관계를 맺는 것이 중요해졌다. 또래로부터 놀이에 수용된 유아가 긍정적인 자아를 형성하고, 유아기에 성공적인 또래관계를 맺은 유아는 이후 학교생활 적 응에서도 긍정적인 영향을 주었다는 연구결과(Buhs \& Ladd, 2001; Jung \& Chi, 2006)들은 유아기의 만족스러운 또래와의 관계 맺기의 중요성을 입증해 주고 있다. 놀이가 유아의 배움 과 경험을 이끄는 중요한 활동으로 간주되면서 다양한 또래관 계 경험을 제공하는 유아교육기관에서의 또래 놀이 상호작용 (E. Choi \& Kim, 2019; Moon \& Choi, 2015)에 초점을 두고 연 구들이 이루어지고 있다.

또래 놀이 상호작용은 유아가 또래와의 다양한 놀이상황에 서 보여주는 행동의 특성을 의미하며, 친사회적이고 순조롭 게 놀이를 이어가는 특성인 놀이 상호작용과 공격적이고 부 정적인 정서 표현인 놀이방해 그리고 위축이나 타인에게 무 시 또는 거부당하는 특징인 놀이단절로 구별된다(Fantuzzo, Coolahan, Mendez, McDermott, \& Sutton-Smith, 1998). 또래 놀 이행동 측정도구 개발(Fantuzzo et al., 1995)에 의해 유아가 또 래와 상호작용을 시도하고 지속하는 과정에서 관찰되는 또래 놀이 상호작용이 유아의 사회적, 정서적 조망능력과 놀이행동 발달(H.-K. Kwon, 2009)에 영향을 미치는지와 유아의 또래 놀 이 상호작용이 유아의 사회적 행동과 유아의 놀이 행동발달에 영향을 미치는지를 검증(Shin, Kwon, \& Jeong, 2010)한 결과 유아는 긍정적 또래 놀이 상호작용을 통해 자신을 이해하고 이를 바탕으로 타인을 존중하며 사회적 정체감의 획득과 사 회적 문제해결 연습의 기회를 갖는 것으로 나타나(Min, 2019; Yoo \& Lee, 2019) 유아의 놀이 발달과 건강한 또래관계를 지원 하기 위해서는 유아의 또래 놀이 상호작용을 향상시키는 노력 이 필요함이 확인되었다.

유아의 또래 놀이 상호작용의 중요성은 하루 중 대부분의 시간을 유아교육기관에 머물며 일상의 놀이를 통해 자연스럽 게 다른 사람과 관계를 맺고, 사회의 중요한 구성원으로 성장 해 간다는 놀이중심 교육과정의 보편적 가치로 자리매김하고 있다. 놀이가 활발히 일어나는 맥락이 또래 놀이 상호작용의 질(Fantuzzo et al., 1995)이라고 인식되고 있는 것이다. 즉, 일상 생활 중 유아가 또래와의 놀이에서 보여주는 다양한 놀이 행 동 특성을 토대로 또래관계를 형성하고 유지할 수 있게 된다. 또래 놀이 상호작용의 중요성에 대한 인식은 유아의 또래 놀 이 상호작용을 긍정적으로 지원하는 방법에 대한 활발한 연
구들로 이어지고 있다. 많은 연구에서 또래 놀이 상호작용의 내용과 그 가치의 결정에 있어 중요 변수로 교사-유아의 관계 나 교사-유아 상호작용(Han \& Huh, 2016; J. Lee, Lee, \& Lee, 2019), 교수효능감(Moon \& Choi, 2015) 또는 교사의 행복감 (Song, Ryu, \& Lee, 2017) 등을 제안하고 있다. 즉, 교사와 유아 의 관계가 능동적이고, 교사와 유아의 상호작용이 활발히 이 루어지면 유아의 또래 놀이 상호작용이 더욱 긍정적이고, 유 아교사의 교수효능감 또는 행복감이 유아의 또래 놀이 상호 작용을 높인다는 것이다. 이러한 연구들은 유아교육기관에서 교사와 유아의 경험들은 상당 부분 교사-유아 상호작용을 통 해 이루어지고(Downer, Sabol, \& Hamre, 2010), 유아의 발달에 교사-유아 상호작용이 직접적으로 영향을 제공함(Dickinson, Darrow, \& Tinubu, 2008)을 근거로 하여 교사의 전문성과 역할 에 초점을 둔 연구가 이루어졌음을 보여주는 것이다.

유아의 놀이를 지원하는 유아교사는 개정 누리과정 해설 서(Lim et al., 2019)에서 개정의 주요 취지에 포함되어 있는 중 요한 요소로, 이상적인 유아교사는 자율성을 기초로 하여 유 아가 놀이를 통해 배운다는 가치에 대한 믿음을 가지고 유아 와 함께, 유아가 중심이 되어 놀이가 살아있는 교육과정을 실 천하는 역할을 수행한다. 더불어 개정 누리과정에서 유아에게 놀이는 생활이며, 유아의 일상생활의 학습과 경험이 놀이중심 으로 이루어지도록 그 실천을 강조하고 있다. 그러나 학습자 중심의 배움의 실현에 있어 유아교사의 교육적 판단은 중요 한 역할을 하기 때문에 교사의 자율성이 강조된다는 점과 유 아에게 놀이가 일상의 대부분을 차지함을 감안하여 또래 놀이 상호작용을 살피는 노력은 상대적으로 저조한 편이다. 따라서 놀이중심 교육과정 안에서 유아의 또래 놀이 상호작용에 영향 을 미치는 교사의 인지적 특성이나 교수의 실제와 같은 선행 변인 연구는 유아의 또래 놀이 상호작용 증진 마련에 실천적 함의가 있으므로 본 연구에서는 유아의 또래 놀이 상호작용에 영향을 미치는 선행변인을 규명해보고자 한다.

유아의 또래 놀이 상호작용은 유아교사의 놀이 가치나 놀 이 실천에 대한 능력, 자신감 등과 같은 변인이 중요하게 작용 할 것으로 예상할 수 있다. 유아교사는 유아들과의 일과활동 에서 유아의 관심과 흥미 그리고 발달에 적합한 활동들을 경 험할 수 있도록 하기 위해 교수법을 사용하고 교수적 판단을 통해 전문성을 발휘하게 된다. 즉 자신의 신념 및 사고에 기초 한 교수행동을 계획하고 실행하며, 놀이 환경과 활동을 선정 하여 수행하게(Wilcox-Herzog \& Ward, 2004) 되는 것이다. 교 사가 교수역할을 수행함에 있어서 자신의 능력에 관한 신념이 나 판단을 교수효능감이라고 하는데(Hwang, 2017), 교수효능 
감은 유아교사가 스스로 어떻게 유아의 활동에 개입하고 참여 할 수 있는가를 인식하여 자신이 유아의 활동에 개입 혹은 참 여하고자 할 때, 자신의 행동이 유아의 활동에 긍정적인 영향 을 줄 것이라는 자신감을 말한다. 교수효능감은 교육의 발전 에 있어서 도움이 되는 요인들과 긍정적인 관계를 맺는 것으 로 알려져 있다(Riggs \& Enochs, 1990). 유아교사의 교수효능 감은 초중등교사와는 다르게 교육적 신념에 기초한 교수 실제 가 중요한 요인으로 작용하며 유아의 성장과 발달에 있어 교 육과정의 기초가 되는 놀이 운영이 그 매개 역할을 하는 것으 로 보고되고 있다(Tschannen-Moran, Hoy, \& Hoy, 1998). 유아 의 또래 놀이 상호작용에 영향을 미치는 선행변인으로서 유아 교사의 교수효능감에 초점을 두고자 하는 것은 놀이운영에 대 한 교육적 신념의 실행인 유아교사의 교수효능감은 교육과정 의 교수내용 및 방법으로서 유아들의 놀이와 활동에 중요한 역할을 하며 유아교사의 실행 능력을 판단하는 중요한 근거를 제공하기(Cheng, 2000) 때문이다. 또한 유아교사의 교수효능 감은 유아와의 일상생활에서 놀이 활동에 대한 지식과 기술로 작용(Spodek \& Saracho, 1990)하게 되므로 유아의 주도적인 경 험과 놀이의 통합적 운영, 유아의 발달 특성을 고려한 놀이중 심 교육과정 실천에 있어서 중요한 역할을 할 것으로 예측되 기 때문이다.

유아교사의 교수효능감의 중요성은 유아의 성장과 발달 에 있어서 교수효능감이 갖는 긍정적인 영향력을 분석한 연 구결과들에 의해 확인되었다. 예를 들어, 유아교사의 교수효 능감은 유아들의 구성놀이 발달 및 놀이 행동발달에 긍정적 으로 영향을 미치는 것으로 나타났다(Shin \& Park, 2006). 교수 효능감이 높은 교사는 유아의 발달과 성취에 대해 적극적인 기대를 하고(Yi \& Choi, 2013), 또래 놀이를 격려하며(Seo \& Park, 2016), 상호작용의 기회를 제공하여 유아의 놀이 발달에 있어 긍정적인 영향을 미치는 것으로 확인되었다(M. S. Kim, Hwang, \& Oh, 2014), 이러한 결과는 유아교사의 교수효능감 이 유아의 또래 놀이 상호작용을 향상시킬 수 있는 잠재력으 로 작용할 수 있음을 시사한다.

유아들의 대부분이 어린이집에서 하루 중 많은 시간을 생 활하며 놀이를 포함한 일상생활이 주로 어린이집에서 이루어 진다는 점과 교육과정 실행의 질이 교사의 역량과 밀접한 관 련이 있음(Ramey \& Ramey, 2000)을 고려하면 어린이집에서 놀이중심 교육과정을 이해하고 교육활동으로 편성하여 실천 하는 등 유아의 일상생활 경험과 놀이 활동의 질에 중요한 역 할을 하는 유아교사의 교수효능감에 대한 탐색은 매우 필요하 고 의미 있다고 하겠다.
유아교사의 교수행동에 대한 신념이나 판단인 교수효능감 은 교사-유아의 상호작용 과정에도 영향을 미칠 수 있다. 교 사-유아의 상호작용이란 어린이집에서 교사와 유아의 정서 적, 언어적 및 행동적 상호작용으로 유아와의 놀이를 포함한 일상생활에서 교사의 전반적인 태도와 행동을 포함하는 것 으로 알려져 있다. 교사-유아의 상호작용은 기본적으로 교사 가 유아와의 놀이에 대해 어떤 가치와 중요성을 가지고 유아 와의 활동에 적절하게 참여하는가와 같은 유아교사의 자신감 에서 비롯된 결과이다(H. J. Kwon, 2012). 높은 수준의 교사-유 아 상호작용은 유아에게 성취하고자 하는 동기를 주고 또래 와 긍정적인 관계를 맺는 기회(M. J. Kim, 2013), 탐색 능력을 향상시킬 수 있는 기회(M. S. Choi \& Hwang, 2007)를 제공하 는 경향이 있고, 유아의 긍정적인 자아발달(Leflot, Onghena, \& Colpin, 2010)과 인지발달을 돕는 것(S.-K. Lee \& Kim, 2016)으 로 알려져 있는데, 이러한 교사-유아의 상호작용은 교사의 교 육과정 실행능력과 교수적 판단을 통한 전문성과 그 맥을 같 이 하기 때문에 교수효능감이 높은 교사가 유아와의 상호작용 의 가치나 중요성에 대해 보다 민감하고 반응적일 것으로 예 측된다.

특히 놀이가 생활인 유아와의 일과 활동을 통해 유아교사 는 놀이에 대한 교수효능감에 의한 교수 행동을 결정하게 되 므로(Shin, 2000; Yi \& Choi, 2013) 교사-유아 상호작용은 놀이 중심 교육과정에서 매우 강조되는 중요한 요인이다(Jeon \& Yi, 2013; Van Hoorn, Nourot, Scales, \& Alward, 2007). 즉 유아 교사는 놀이 활동을 포함한 일상적 양육과 상호작용을 통해 유아의 개별적 차이를 존중하게 되는데 유아교사가 유아와 함 께 경험하는 놀이중심 활동에 대해 어떠한 교수효능감을 가지 고 있는가에 따라 유아의 발달에 적합한 교사-유아의 상호작 용을 제공할 수 있게 되는 것이다.

Vygotsky (1978)는 높은 수준의 근접발달영역(zone of proximal development)의 형성은 성인이나 더 유능한 또래와의 상호작용에 의해 촉진되며, 성인이나 유능한 또래가 높은 수 준의 사고나 행동을 요구하는 상황을 만드는 것에 의해서라 고 밝히고 있다. 즉, 유아교사나 또래는 상호작용을 통해 유아 의 높은 수준의 사고나 행동 발달을 도움으로써 유아의 성장 을 효과적으로 스캐폴드 할 수 있게 되는 것이다. 어린이집에 서 이루어지는 다양한 놀이와 일상생활 활동들은 교사-유아 의 상호작용을 통하여 이루어지기 때문에 교사가 유아의 개별 적이고 발달적인 상황을 고려하여 민감하고 지속적인 정서적, 언어적 및 행동적 상호작용을 시도해주면 보육실의 전반적인 분위기가 안정되고 유아의 자존감 및 또래들과의 긍정적 상호 
작용 향상에 도움을 줄 수 있을 것으로 예측된다. 유아의 또래 놀이 상호작용은 유아가 어린이집에서 또래와의 하루 일과 중 놀이를 포함한 일상생활을 통해 보여주는 다양한 행동 특성을 의미하므로 유아와의 상호작용이 갖는 중요성과 가치를 교사 가 보다 긍정적으로 인식하여 실천하는 것과 깊이 관련이 있 을 것으로 예상할 수 있다. 교사가 유아와 친밀하고 온정적인 관계를 형성한 경우 긍정적인 교사-유아 상호작용이 많이 이 루어지고 이를 통해 유아의 또래 놀이 상호작용에 긍정적인 영향을 미쳤다는 선행연구(J. Lee et al., 2019)에 비추어 볼 때 어린이집에서 교사-유아의 상호작용이 유아의 놀이를 포함한 일상생활 경험에서의 또래 놀이 상호작용에 영향력을 갖는 주 요한 선행변인인지 탐색해 볼 필요가 있다.

그러나 또래 놀이 상호작용과 교사-유아 상호작용의 관계 를 탐색한 선행연구는 유아의 기질적 특성에 주목하여 놀이와 수업 중의 유아 개인차에 관심을 두고 그 관계를 탐색한 연구 가 대부분이다. 유아 개인이 자신과 환경과의 상호작용 과정 에서 자유롭게 놀이를 선택하고 실행하게 되는 자유선택활동 시간에 주목하여 탐색한 연구가 많은 것이다. 이는 유아와 교 사가 어린이집에서 흥미영역으로 구성된 활동이 있는 자유선 택활동을 놀이공간으로 인식(S.-Y. Cho \& Park, 2014) 한 것에 서 비롯된 것으로 어린 연령부터 하루 중 긴 시간을 어린이집 에서 생활하며 일상생활 자체를 놀이로 받아들이는 유아들과 일상생활을 통합하여 놀이중심 교육을 실천하는 유아교사의 관점에서 또래 놀이 상호작용을 적극 지원할 수 있는 방안을 모색하는 노력이 필요하다.

이상의 선행연구들을 근거로 볼 때 어린이집에서 유아교사 의 교수효능감은 또래 놀이 상호작용에 직접적 영향을 주기도 하지만 유아교사의 교수효능감이 교사-유아의 상호작용 형성 에 영향을 미치고, 이렇게 형성된 교사-유아의 상호작용이 또 래 놀이 상호작용에 영향을 줄 것으로 예상해 볼 수 있다. 즉, 수준 높은 유아교사의 교수효능감은 높은 수준의 교사-유아 상호작용으로 나타나고, 유아교사의 교수효능감은 보다 긍정 적인 교사-유아 상호작용을 형성하여 수준 높은 또래 놀이 상 호작용으로 그 영향력을 미치게 될 것이다. 이는 교수효능감 이 높은 유아교사는 놀이중심 교육과정의 실천에 있어서 유아 의 발달에 적합한 놀이를 포함한 일상생활의 교수행동을 통해 유아의 또래 놀이행동 발달을 돕는 역할을 할 가능성이 있기 때문이다. 또한 높은 수준의 교사-유아의 상호작용은 놀이에 대한 교육적 신념의 실행인 유아교사의 교수효능감에 근거하 여 유아의 또래 놀이 상호작용에 긍정적인 경험을 유도할 것 으로 기대할 수 있다.
따라서 본 연구에서는 유아교사의 교수효능감 수준이 교 사-유아의 상호작용에 영향을 줄 것이며, 그 영향이 유아의 또 래 놀이 상호작용에 미치게 된다는 것을 매개효과를 통해 확 인해 보고자 한다. 이로써 유아교사의 교수효능감과 교사-유 아의 상호작용을 증진시킬 수 있는 방법을 찾는 기초자료로 활용될 수 있을 것이며 더불어 놀이중심 교육과정의 통합적 운영을 위한 교사교육 자료를 제공할 수 있을 것이다. 이를 위 해 다음과 같이 연구문제와 연구모형을 선정하였다(Figure 1).

\section{연구문제 1}

유아교사의 교수효능감, 교사-유아 상호작용 및 유아의 또래 놀이 상호작용 간의 상관관계는 어떠한가?

\section{연구문제 2}

유아의 또래 놀이 상호작용에 대한 유아교사의 교수효능감의 영향은 교사-유아 상호작용에 의해 매개되는가?

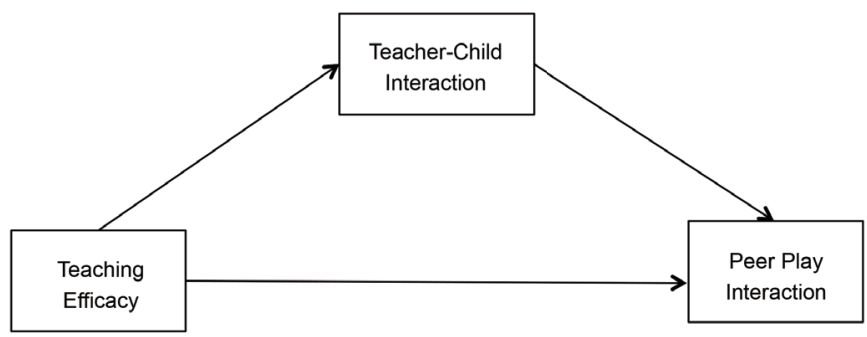

Figure 1. Study model.

\section{Methods}

\section{연구대상}

본 연구의 대상은 한국아동패널 (Panel Study of Korea Children [PSKC]) 데이터의 7차년도(2014) 자료 중 만 6세 유아 403명 과 유아의 어린이집 담임교사 403 명이다. 연구대상의 일반적 특성은 Table 1 과 같다.

연구대상 유아교사들이 근무하고 있는 어린이집 시설유 형은 민간어린이집(61.0\%)이 가장 많았고, 국공립어린이집 (18.6\%), 법인어린이집(14.9\%)의 순으로 나타났다. 담당유아 의 성별은 남아가 $53.8 \%$, 여아는 $46.2 \%$ 로 나타났다. 교사연 령은 30-39세(44.4\%)가 가장 많았고, 20-29세(33.7\%), 40-49 세(20.1\%)의 순이었다. 최종학력은 전문대 재학 및 졸업자가 $47.4 \%$ 로 가장 많았고 대학교 재학 및 졸업자가 $35.2 \%$, 대학 
Table 1

Descriptive Characteristics of the Participants

\begin{tabular}{|c|c|c|c|}
\hline & Variables & $n$ & $\%$ \\
\hline \multirow[t]{6}{*}{ Child care center type } & National public childcare center & 75 & 18.6 \\
\hline & Corporation childcare center & 60 & 14.9 \\
\hline & Private childcare center & 246 & 61.0 \\
\hline & Workplace childcare center & 18 & 4.5 \\
\hline & Home childcare center & 2 & .5 \\
\hline & Parent cooperative childcare center & 2 & .5 \\
\hline \multirow[t]{2}{*}{ Children's gender } & Male (Boy) & 217 & 53.8 \\
\hline & Female (Girl) & 186 & 46.2 \\
\hline \multirow[t]{4}{*}{ Teacher's age (Years) } & $20-29$ & 136 & 33.7 \\
\hline & $30-39$ & 179 & 44.4 \\
\hline & $40-49$ & 81 & 20.1 \\
\hline & $50-59$ & 7 & 1.7 \\
\hline \multirow[t]{4}{*}{ Education } & Graduation from high school and lifelong education center & 52 & 12.9 \\
\hline & Enrolled students and graduates of college & 191 & 47.4 \\
\hline & Enrolled students and graduates of university & 142 & 35.2 \\
\hline & Graduates of graduate school & 18 & 4.5 \\
\hline \multirow[t]{4}{*}{ Major } & Child studies & 59 & 14.6 \\
\hline & Early childhood education & 191 & 47.4 \\
\hline & Childcare & 51 & 12.7 \\
\hline & Others (Including non-responses) & 102 & 25.3 \\
\hline
\end{tabular}

Note. $N=403$.

원 이상의 학력 소지자가 $4.5 \%$ 였다. 유아교사의 전공은 유아 교육(47.4\%), 아동학(14.6\%), 보육학(12.7\%)의 순으로 나타났 다.

\section{연구도구}

본 연구에서는 한국아동패널 자료의 문항내용을 참고하여 구 성한 척도들을 사용하였으며 연구에 활용된 척도들은 다음과 같다.

\section{유아교사의 교수효능감}

한국아동패널의 '교수효능감' 척도는 Y. H. Kim과 Kim (2008) 이 Bandura (2006)의 교사의 자기효능감 척도 Teacher Selfefficacy Scale (TSES)를 근거로 요인구조를 분석한 문항을 한국 아동패널의 연구진이 일부 수정하여 사용하였다. Y. H. Kim과 $\operatorname{Kim}$ (2008)의 척도는 가정연계와 긍정적 학습환경 조성효능 감, 교수효능감 및 지역기관 연계효능감 그리고 의사결정 참 여효능감 영역으로 구성되었는데 한국아동패널에서는 교수
효능감을 측정하는 7 문항을 사용하였다. 교수효능감은 "교육 활동에 흥미가 적은 아이들을 지도할 경우, 그 아이들의 동기 를 유발할 수 있다.", "아이들이 협력하여 활동하도록 이끌 수 있다.”와 같은 문항으로 구성되어 있다. 검사문항은 5점 Likert 척도로 평정되며 점수가 높을수록 유아교사의 교수효능감 수 준이 높은 것을 의미한다. 교수효능감 전체 요인의 내적합치 도(Cronbach’s $\alpha$ )는 .86으로 나타났다.

$$
\text { 교사-유아의 상호작용 }
$$

한국아동패널의 '교사-유아 상호작용' 척도는 Bredekamp (1985)의 Early Childhood Observation Instrument (ECOI)를 Holloway와 Reichhart-Erickson (1988)이 일부 수정하여 사용한 문항들을 한국아동패널 연구진이 번역하여 사용하였다. 이 척 도는 "아이에게 애정과 신뢰를 가지고 자주 상호작용한다.", "아이의 발달 수준에 적합한 독립적 행동을 격려해 준다."와 같은 교사가 유아와 얼마나 온정적이고, 반응적이며 긍정적으 로 상호작용하는지를 측정하기 위한 문항으로 구성되어 있다. 본 도구는 총 10 문항이며 Likert식 5점 척도를 사용하였다. 점 
Table 2

Means, Standard Deviations, and Correlations Among Variables

\begin{tabular}{|c|c|c|c|c|c|}
\hline Variables & 1 & 2 & 3 & 4 & 5 \\
\hline 1. Teaching efficacy & - & & & & \\
\hline 2. Teacher-child interaction & $.743^{* *}$ & - & & & \\
\hline 3. Play interaction & $.235^{* *}$ & $.225^{* *}$ & - & & \\
\hline 4. Play disruption & $-.178^{* *}$ & $-.173^{* *}$ & $-.250^{* *}$ & - & \\
\hline 5. Play disconnection & $-.219^{* *}$ & $-.256^{* *}$ & $-.483^{* *}$ & $.551^{* *}$ & - \\
\hline$M$ & 3.88 & 4.21 & 3.07 & 2.12 & 1.65 \\
\hline$S D$ & 0.50 & 0.50 & 0.45 & 0.49 & 0.55 \\
\hline
\end{tabular}

Note. $N=403$.

${ }^{* *} p<.01$.

수가 높을수록 교사-유아의 상호작용 수준이 높은 것으로 평 가된다. 본 연구의 내적합치도(Cronbach's $\alpha$ )는 .91이었다.

\section{유아의 또래 놀이 상호작용}

한국아동패널의 '또래 놀이 상호작용' 척도는 Fantuzzo 등 (1998)의 아동의 또래 놀이행동 척도 Peen Interactive Peer Play Scale (PIPPS)와 H. Y. Choi와 Shin (2008)의 PIPPS의 국내적용 을 위한 타당화 연구의 내용을 참고하여 한국아동패널의 연구 진이 재구성하여 사용하였다. 이 도구는 놀이 상호작용, 놀이 방해 및 놀이단절 3 개 하위영역으로 각각 9문항, 13 문항, 8 문 항으로 구성되어 있다. 놀이 상호작용은 친사회적인 특성들과 놀이를 순조롭게 이어가는 특성 등이 담긴 문항으로 구성되어 있다. 문항의 예시로는 “친구에게 함께 놀자고 한다." "친구와 의 놀이에서 긍정적 감정을 표현한다.”와 같은 것이다. 놀이방 해는 공격적이고 부정적인 정서 표현 등을 의미하며, "친구에 게 언어적 비난을 한다.”, “친구와의 상호작용에서 신체적 공 격성을 보인다.”와 같은 문항이다. 놀이단절은 위축 혹은 타인 에게 무시 또는 거부당하는 특징을 말하며, "목적 없이 돌아다 닌다.", "놀이에서 혼란스러워 한다.”와 같은 문항으로 구성되 었다. 본 도구는 4점 Likert식 척도로 부정적인 상호작용을 의 미하는 놀이방해와 놀이단절에 연관된 문항은 역 채점하여 높 은 점수 일수록 또래 놀이 상호작용이 긍정적인 것을 의미한 다. 각 하위요인의 내적합치도(Cronbach's $\alpha$ )는 놀이 상호작용 .81 , 놀이방해 .85, 놀이단절 .87로 나타났다.

\section{자료분석}

본 연구에서는 SPSS 25.0 (IBM Co., Armonk, NY)와 SPSS
PROCESS macro version 3.4 (Hayes, 2017)를 사용하여 분석하 였다. 연구문제 고찰에 앞서 측정도구의 신뢰도를 파악하기 위해 Cronbach's $\alpha$ 계수를 산출하였고, 연구대상의 특성을 파 악하기 위해 빈도분석을 실시하였으며, 각 변인의 평균과 표 준편차를 구하였다. 구체적인 연구문제 고찰을 위해 Pearson 상관관계분석을 실시하고, PROCESS macro version 3.4 프로그 램의 Model 4 를 이용하여 검증하였다. 매개효과의 유의성 검 증을 위해 부트스트래핑(bootstrapping) 방법을 사용하였으며, 부트스트랩 샘플은 5,000개로 지정하고 신뢰구간은 95\%로 설 정하여 분석하였다.

\section{Results}

연구결과의 제시에 앞서 각 변인의 일반적인 경향을 알아보기 위해 기술통계와 Pearson의 상관계수는 Table 2 와 같다.

\section{유아교사의 교수효능감과 교사-유아 상호작용, 유아의 또래 놀이 상호작용의 관계}

유아교사의 교수효능감과 교사-유아 상호작용, 유아의 또래 놀 이 상호작용의 기술적인 통계를 살펴보면, 유아교사의 교수효 능감 평균은 5점을 기준으로 할 때 평균 3.88점으로 보통보다 높은 수준이었으며 교사-유아의 상호작용의 평균은 5점 기준 4.21점으로 높게 나타났다. 유아의 또래 놀이 상호작용의 평균 을 하위 영역별로 나누어 보면 4점 기준으로 놀이 상호작용이 3.07점, 놀이방해는 2.12점, 놀이단절은 1.65 점으로 나타났다.

유아교사의 교수효능감, 교사-유아 상호작용 및 유아의 또 래 놀이 상호작용의 상관관계를 살펴보면, 유아교사의 교수효 
Table 3

Effects of Teaching Efficacy of Early Childhood Teachers and Teacher-Child Interactions on the Play Interaction of Young Children

\begin{tabular}{|c|c|c|c|c|c|c|c|c|c|}
\hline \multirow[b]{2}{*}{ Predictors } & \multicolumn{3}{|c|}{ Play interaction } & \multicolumn{3}{|c|}{ Teacher-child interaction } & \multicolumn{3}{|c|}{ Play interaction } \\
\hline & $B$ & $S E$ & $t$ & $B$ & $S E$ & $t$ & $B$ & $S E$ & $t$ \\
\hline Teaching efficacy & .212 & .044 & $4.837^{* * *}$ & .736 & .033 & $22.225^{* * *}$ & .136 & .065 & $2.078^{*}$ \\
\hline$F\left(d f_{1}, d f_{2}\right)$ & \multicolumn{3}{|c|}{$23.400^{* * *}(1,401)$} & \multicolumn{3}{|c|}{$493.956^{* * *}(1,401)$} & \multicolumn{3}{|c|}{$12.975^{* * *}(2,400)$} \\
\hline$R^{2}$ & \multicolumn{3}{|c|}{.055} & \multicolumn{3}{|c|}{.552} & \multicolumn{3}{|c|}{.061} \\
\hline
\end{tabular}

Note. $N=403$.

${ }^{*} p<.05 .{ }^{* * *} p<.001$.

Table 4

Effects of Teaching Efficacy of Early Childhood Teachers and Teacher-Child Interactions on the Play Disruption of Young Children

\begin{tabular}{|c|c|c|c|c|c|c|c|c|c|}
\hline \multirow[b]{2}{*}{ Predictors } & \multicolumn{3}{|c|}{ Play disruption } & \multicolumn{3}{|c|}{ Teacher-child interaction } & \multicolumn{3}{|c|}{ Play disruption } \\
\hline & $B$ & $S E$ & $t$ & $B$ & $S E$ & $t$ & $B$ & $S E$ & $t$ \\
\hline Teaching efficacy & -.173 & .048 & $-3.620^{* * *}$ & .736 & .033 & $22.225^{* * *}$ & -.108 & .071 & -1.511 \\
\hline$F\left(d f_{1}, d f_{2}\right)$ & \multicolumn{3}{|c|}{$13.103^{* * *}(1,401)$} & \multicolumn{3}{|c|}{$493.956^{* * *}(1,401)$} & \multicolumn{3}{|c|}{$7.316^{* *}(2,400)$} \\
\hline$R^{2}$ & \multicolumn{3}{|c|}{.032} & \multicolumn{3}{|c|}{.552} & \multicolumn{3}{|c|}{.035} \\
\hline
\end{tabular}

Note. $N=403$.

${ }^{* *} p<.01 .{ }^{* * *} p<.001$.

능감은 교사-유아의 상호작용 $(r=.743, p<.01)$, 유아의 또래 놀이 상호작용의 하위영역인 놀이 상호작용 $(r=.235, p<.01)$ 과 정적 상관관계를, 놀이방해와 놀이단절 $(r=-.178, p<.01 ; r$ $=-.219, p<.01)$ 과는 부적 상관관계를 나타냈다.

\section{유아교사의 교수효능감과 유아의 또래 놀이 상호작용에 미치는 영향에 대한 교사-유아 상호작용의 매개효과}

유아교사의 교수효능감이 유아의 또래 놀이 상호작용에 미치 는 영향에 대한 교사-유아 상호작용의 매개효과를 파악하기 위하여 Hayes (2017)의 PROCESS macro version 3.4 (Model 4) 를 활용하여 분석을 실시하였다.

먼저 유아의 또래 놀이 상호작용의 하위영역인 놀이 상호 작용에 대한 유아교사의 교수효능감과 교사-유아 상호작용의 영향을 분석한 결과, Table 3에 제시된 바와 같이 유아교사의 교수효능감은 교사-유아 상호작용에 유의한 영향을 미치고 $(B$ $=.736, p<.001)$, 교사-유아 상호작용은 유아의 놀이 상호작용 에 유의한 영향을 미치지 않았다. 또한 교수효능감과 놀이 상 호작용 간 총 효과는 $B=.212(p<.001)$ 이었으나 매개변수인 교사-유아 상호작용이 투입되면서 교수효능감에서 놀이 상호
작용 간 경로의 직접 효과만 유의한 것으로 나타났다 $(B=.136$, $p<.05)$. 이를 통하여 볼 때 유아교사의 교수효능감과 유아의 놀이 상호작용 사이에서 교사-유아 상호작용의 매개효과는 없는 것으로 확인되었다.

다음으로 유아의 또래 놀이 상호작용의 하위영역인 놀이 방해에 대한 유아교사의 교수효능감과 교사-유아 상호작용의 영향을 살펴보면, Table 4에서 유아교사의 교수효능감은 교사유아 상호작용에 유의한 영향을 주었으나 $(B=.736, p<.001)$, 교사-유아 상호작용은 유아의 놀이방해에 유의한 영향을 미 치지 않았다. 또한 매개변수인 교사-유아 상호작용이 투입되 면서 교수효능감에서 놀이 상호작용 간 경로는 유의하지 않은 것으로 나타났다. 이를 통해 유아교사의 교수효능감과 놀이방 해 사이에서 교사-유아 상호작용의 매개효과는 없는 것으로 밝혀졌다.

마지막으로 유아의 또래 놀이 상호작용의 하위영역인 놀이 단절에 대한 유아교사의 교수효능감과 교사-유아 상호작용의 영향을 분석한 결과, Table 5 와 같이 교수효능감은 교사-유아 상호작용에 유의한 영향을 미치고 $(B=.736, p<.001)$, 교사-유 아 상호작용은 놀이단절에 유의한 영향을 주어 $(B=-.233, p<$ .01) 교사-유아 상호작용이 교수효능감과 놀이단절 간의 관계 에서 매개하였다. 또한 교수효능감과 놀이단절 간 총 효과는 
Table 5

Effects of Teaching Efficacy of Early Childhood Teachers and Teacher-Child Interactions on the Play Disconnection of Young Children

\begin{tabular}{|c|c|c|c|c|c|c|c|c|c|}
\hline \multirow[b]{2}{*}{ Predictors } & \multicolumn{3}{|c|}{ Play disconnection } & \multicolumn{3}{|c|}{ Teacher-child interaction } & \multicolumn{3}{|c|}{ Play disconnection } \\
\hline & $B$ & $S E$ & $t$ & $B$ & $S E$ & $t$ & $B$ & $S E$ & $t$ \\
\hline Teaching efficacy & -.241 & .054 & $-4.486^{* * *}$ & .736 & .033 & $22.225^{* * *}$ & -.069 & .079 & -.869 \\
\hline$F\left(d f_{1}, d f_{2}\right)$ & \multicolumn{3}{|c|}{$20.125^{* * *}(1,401)$} & \multicolumn{3}{|c|}{$493.956^{* * *}(1,401)$} & \multicolumn{3}{|c|}{$14.482^{* * *}(2,400)$} \\
\hline$R^{2}$ & \multicolumn{3}{|c|}{.048} & \multicolumn{3}{|c|}{.552} & \multicolumn{3}{|c|}{.068} \\
\hline
\end{tabular}

Note. $N=403$.

${ }^{* *} p<.01{ }^{* * *} p<.001$.

Table 6

Verification of the Mediation Effect of Teacher-Child Interactions on the Relationship Between Teaching Efficacy and Play Disconnection

\begin{tabular}{llccc}
\multicolumn{1}{c}{ Paths } & \multicolumn{1}{c}{ 95\% CI of indirect effect } \\
\hline Total effect & $B$ & $S E$ & \multicolumn{2}{c}{ Lower } \\
Direct effect & $-.2406^{* * *}$ & .0536 & -.3460 & -.1352 \\
Indirect effect & -.0690 & .0794 & -.2251 & .0871 \\
\hline
\end{tabular}

${ }^{* *} p<.01 .{ }^{* * *} p<.001$.

$B=-.241(p<.001)$ 이었으나 매개변수인 교사-유아 상호작용 이 투입되면서 교수효능감에서 놀이단절 간 경로의 간접 효과 만 유의한 것으로 나타나 교사-유아 상호작용이 매개하였음 을 알 수 있다. 교수효능감이 교사-유아 상호작용에 유의미한 영향을 미치고 교사-유아 상호작용은 놀이단절에 유의미한 영향을 미치는 점, 그리고 교수효능감과 놀이단절 간 경로의 직접효과는 사라지고 간접효과만 있다는 점은 매개효과가 있 음을 의미한다. 이와 같은 결과를 통하여 교사-유아 상호작용 은 유아교사의 교수효능감과 유아의 놀이단절 사이에서 매개 역할을 하고 있음을 검증하였다.

추가로 유아교사의 교수효능감과 놀이단절의 간접 효과를 검증하기 위하여 부트스트래핑(bootstrapping) 검증을 실시하 였다(Table 6). 그 결과 부트스트랩의 상한 값과 하한 값 사이 에 0이 존재하지 않아 간접 효과는 유의한 것으로 밝혀졌다. 즉, 유아교사의 교수효능감의 수준이 높을수록 높은 수준의 교사-유아 상호작용으로 이어져 놀이단절이 감소할 것이라는 가설이 지지되었다.

\section{Discussion}

본 연구는 유아교사의 교수효능감과 유아의 또래 놀이 상호작 용과의 관계를 알아보고, 유아교사의 교수효능감이 유아의 또
래 놀이 상호작용에 영향을 미치는 과정에서 교사-유아 상호 작용이 매개 역할을 하는지 검증해 보고자 하였다. 본 목적을 수행하기 위해 육아정책연구소에서 제공하는 한국아동패널 제 7차 자료에서 어린이집에 다니고 있는 취학 전 만 6세 유아 와 유아의 담임교사를 대상으로 검증하였다. 분석된 연구결과 를 바탕으로 다음과 같이 결론을 도출하였다.

첫째, 유아교사의 교수효능감은 교사-유아 상호작용, 유아 의 또래 놀이 상호작용의 하위요인인 놀이 상호작용과는 정적 상관관계가, 놀이방해와 놀이단절과는 부적 상관관계가 있는 것으로 나타났다. 이는 유아교사의 교수효능감의 질적 수준이 높을수록 교사-유아 상호작용과 유아의 놀이 상호작용의 수 준이 높게 나타나며, 놀이방해와 놀이단절은 낮춤으로써 교 사-유아 상호작용, 유아의 또래 놀이 상호작용 간에 서로 관련 이 있음을 의미한다. 이러한 결과는 교사-유아 상호작용과 교 수효능감이 유아의 또래 놀이 상호작용과 정적, 부적인 상관 이 있음을 보고한 연구(Han \& Huh, 2016)를 지지하는 것이며, 교사의 교수효능감과 교수행동이 유아의 발달과 성장에 긍정 적인 영향을 미친다고 밝힌 연구결과(Shin \& Park, 2006)와 일 관된 것이다. 즉, 유아교사 자신이 유아와의 놀이를 포함한 일 상생활의 가치와 중요성을 인식하여 이를 교수행동으로 실천 하고자 하는 능력과 자신감이 높을수록 유아들과의 정서적, 언어적 및 행동적 상호작용에 적극적인 행동을 하는 것으로 예측할 수 있다. 이는 또한 유아가 부정적인 정서를 사회적으 
로 적합한 방법으로 일상생활뿐만 아니라 놀이 활동에서 자연 스럽게 표출하도록 함으로써 순조롭게 놀이를 이어가고, 갈등 상황이 발생되는 부정적인 행동이나 사회적 기술의 미흡 등으 로 놀이를 연결하지 못하는 행동을 감소시키는 것으로 추론해 볼 수 있다.

둘째, 유아교사의 교수효능감은 교사-유아 상호작용을 매 개로 유아의 또래 놀이 상호작용의 하위요인인 놀이단절에 영 향을 미쳤다.

먼저, 유아교사의 교수효능감이 교사-유아 상호작용에 유 의한 영향을 미치는 것으로 나타나, 유아와의 일상생활 및 놀 이에서의 교육적 신념이나 자신감이 교사-유아 상호작용에 중요하게 작용한다는 것을 확인 할 수 있었다. 교수효능감 이 높은 교사는 유아의 능력에 기대감을 가지고 다양한 기회 를 제공하며 긍정적인 반응으로 유아를 지원한다(Gibson \& Dembo, 1984; Yi \& Choi, 2013)고 알려져 있다. 즉 교수효능감 수준이 높은 유아교사는 유아와의 놀이를 포함한 일상생활에 서 반응적이며, 유아의 의견을 존중해주고 유아의 느낌이나 사고를 격려하는 정서적, 언어적 및 행동적 상호작용을 시도 하는 것으로 해석될 수 있다. 이는 놀이에 대한 교사효능감이 높은 교사는 격려와 확장의 상호작용을 많이 하는 반면, 놀이 에 대한 교사효능감이 낮은 교사는 유아의 놀이를 방해하거나 회피하도록 하는 상호작용을 많이 하게 된다는(Shin, 2000) 연 구결과와 같은 맥락으로 유아교사의 교수효능감과 교사-유아 상호작용의 관계가 이해될 수 있다. 또한 유아들의 놀이와 활 동에서 교수효능감이 중요한 역할을 하며 유아교사의 실행 능 력을 판단하는 근거를 제공한다(Cheng, 2000)는 연구결과에 비추어 볼 때, 유아의 일상생활을 포함한 놀이에 적절하게 개 입하고 참여할 수 있으며 유아에게 긍정적인 영향을 줄 수 있 다는 유아교사의 자신감은 수준 높은 교사와 유아의 정서적, 언어적 및 행동적 상호작용을 형성하도록 한다고 할 수 있다.

다음으로, 교사-유아 상호작용은 유아의 또래 상호작용의 하위 요인인 놀이단절에 부적 영향을 미치는 것으로 나타났 다. 즉, 유아교사가 유아의 개별적이고 발달적인 상황을 고려 한 민감하고 지속적인 정서적, 언어적 및 행동적 상호작용을 시도함으로써 놀이뿐만 아니라 일과활동에서 소외되거나 사 회적 기술의 부족으로 놀이 참여에 어려움을 겪는 유아의 놀 이단절을 낮추는 것으로 해석할 수 있다. 이러한 결과는 놀이 의 진입에 어려움을 겪거나 놀이에서의 또래 갈등과 같은 또 래 상호작용이 교사의 개입에 따라 달라진다고 밝힌 연구결 과(Holloway \& Reichhart-Erickson, 1988; Stanton-Chapman \& Hadden, 2011)를 지지한다. 또한 교사가 유아의 놀이를 격려
하고 참여하며 적절한 상호작용을 시도했을 때 발달과 학습에 긍정적인 영향을 미치는 것으로 나타난 연구결과(S. L. Kim \& Park, 2015; Trawick-Smith \& Dziurgot, 2011)와도 같은 맥락에 서 볼 수 있다. 이는 유아교사가 또래의 무시나 거부 혹은 사회 적 기술의 부족으로 놀이를 포함한 일상생활에서 어떻게 할지 몰라 뒤로 물러서 있는 유아의 참여를 격려하고 유아의 흥미 를 유발하는 정서적, 언어적 및 행동적 상호작용을 수행하는 것으로 해석할 수 있다.

더불어 유아교사의 교수효능감은 놀이단절에 직접적인 영 향을 미치지만 교사-유아 상호작용과 함께 놀이단절에 미치 는 영향을 살펴보았을 경우에는 유아교사의 교수효능감이 또 래 놀이 상호작용의 하위요인인 놀이단절에 미치는 직접적인 영향은 사라지고 교사-유아 상호작용을 매개로 한 경우에만 놀이단절에 영향을 미쳤다. 유아교사의 교수효능감은 직접적 으로 유아의 놀이단절에 영향을 주기보다는 교사-유아의 상 호작용이라는 교수행동 형성에 영향을 미치고, 이렇게 형성 된 교사-유아 상호작용이 유아의 또래 놀이 상호작용의 하위 요인인 놀이단절에 영향을 미치는 것으로 나타났다. 이는 유 아교사의 교육적 신념과 자신감에 의해 이루어진 구체적인 교 수행동(Stipek \& Byler, 1997)인 교사-유아 상호작용이 유아의 놀이단절에 직접적으로 의미 있는 영향을 미치는 것으로 해 석될 수 있다. 교사-유아 상호작용과 또래 상호작용은 서로 관 련이 있고(Moon \& Choi, 2015; Shim \& Lim, 2017), 놀이 진입 의 어려움이나 또래 갈등과 같은 놀이에서의 또래 상호작용이 구체적인 교사의 개입 행동에 의해 영향을 받는다는 선행연 구(Park \& Hwang, 2012; Stanton-Chapman \& Hadden, 2011)를 지지하는 이 연구결과는 교사-유아의 상호작용이 구체적으로 유아의 또래 놀이 상호작용의 하위요인인 놀이단절에 영향을 주고 있음을 보여주고 있다. 즉, 높은 수준의 교사-유아의 상 호작용은 교수행동의 계획과 실행에 기초가 되는 유아교사의 교수효능감을 근거로 하여, 유아의 일상생활 및 놀이에서 유 아의 또래 놀이를 격려하고 자발적인 동기를 갖도록 지원하며 놀이단절을 낮추도록 한다고 볼 수 있다.

한편 본 연구결과에서 제시한 바와 같이 유아교사의 교수 효능감이 유아의 또래 놀이 상호작용의 하위요인인 놀이 상 호작용과 놀이방해에 의미 있는 영향을 미치고 있다는 점에 도 주목할 필요가 있다. 유아교사의 교수효능감이 유아의 놀 이 상호작용에 의미 있는 영향을 준다는 것은 유아와의 활동 에 적절한 개입과 참여를 할 수 있는지를 스스로 인식하고 자 신의 행동이 유아의 활동에 긍정적인 영향을 줄 것이라는 자 신감을 가진 유아교사가 유아의 놀이 상호작용에 대한 긍정 
적인 기대를 하고 또래 놀이를 격려하여 유아에게 다양한 놀 이 상호작용의 기회를 제공한다고 해석할 수 있다. 교사가 유 아와의 놀이를 포함한 일상생활을 이해하고 이를 바탕으로 적 절히 유아를 지원하기 위해서는 유아의 놀이상황을 집중력 있 게 관찰하는 것이 필요하다. 교사가 유아의 놀이를 관심 있게 지켜보는 것은 유아의 놀이를 지원하는 가장 기본적인 형태 이자 본격적인 놀이 참여의 기초가 되기 때문이다(Gadamer, 1960/2000). 유아교사는 하루 중 긴 시간을 어린이집에서 생 활하는 유아를 하루 일과 중에 자연스럽게 관찰하게 된다. 교 수효능감 수준이 높은 유아교사의 관찰은 유아들의 일상생활 및 놀이의 흐름과 맥락, 주제와 에피소드 등 유아를 총체적으 로 이해할 수 있는 요소들을 포함하게 될 것으로 예상할 수 있 다. 이는 높은 수준의 유아교사의 교수효능감이 개별 유아를 이해하고자 하는 상황에 자연스럽게 접근할 수 있도록 돕는 것이다. 그리고 유아는 하루 중 긴 시간을 자신의 놀이를 스스 로 선택하여 참여하고 오전의 활동을 오후의 활동으로 확장할 수 있는 기회를 갖게 된다(Hong, Kim, Kang, \& Kim, 2007; K. $\mathrm{Kim} \& \mathrm{Kim}, 2007)$. 이는 유아가 주도적으로 활동에 대한 계획 과 결정을 내리는 경험을 하는 것이 또래와의 활동에 더 긍정 적으로 몰입하여, 애정적이며 신뢰로운 학급 분위기를 형성하 게 되고(Suh \& Lee, 2011; Vitiello, Booren, Downer, \& Williford, 2012), 어린이집 교사들이 유아의 흥미를 고려한 개별화 교육 에 있어서 교수학습방법의 실행 정도가 높게 나타났다(S.-Y. Cho \& Lee, 2014)는 연구결과의 연장선상에서 해석해 볼 수 있다. 즉 교수효능감 수준이 높은 유아교사는 유아의 놀이를 포함한 일상생활의 총체적 관찰을 통해 유아의 발달 수준과 흥미를 이해하고 이를 바탕으로 유아에게 적합한 놀이 환경을 조성하며, 긍정적이고 수용적인 분위기에서 유아가 스스로 행 동을 계획 및 실행, 평가하는 기회를 갖게 하여 긍정적이고 원 활한 놀이 상호작용을 지원하게 되는 것이다.

또한 유아교사의 교수효능감이 유아의 놀이방해에 의미 있 는 영향을 미치고 있다는 것은 수준 높은 유아교사의 교수효 능감은 기본적으로 유아들 사이의 공격적이고 부정적인 정서 표현이 발생하는 일상생활 및 놀이상황을 유아들이 스스로 해 결해 볼 수 있는 기회를 제공하는 것으로 해석할 수 있다. 교수 효능감이 높은 교사는 유아가 놀이를 포함한 일상생활 속에서 겪는 여러 가지 사회적 어려움에 동감하고 그 맥락을 잘 이해 함으로써 어려움을 잘 극복할 수 있도록 돕는 것이다. 이러한 특성은 놀이중심 교육과정의 실천에 있어서 유아의 주도적인 경험을 지원하는 유아교사의 교육적 시도와 노력이 중요함을 보여주고 있다. 유아의 활동에서 교사의 참여는 자칫 유아의
놀이 자발성과 선택의 자유를 제한 할 위험성을 포함하고 있기 때문에(Fumoto, 2011; Wing, 1995) 교사가 유아의 일상생활 경 험과 놀이 활동의 다양성 그리고 유아의 개별성을 고려하면서 가장 낮은 수준의 주도성을 갖는 개입부터 높은 수준의 주도성 을 갖는 개입까지 다양한 참여의 방식으로 지원하는 것이 중요 하다. 따라서 높은 수준의 교수효능감을 가진 유아교사는 일 상생활 경험과 더불어 놀이 활동에서 또래와의 갈등이나 문제 상황은 유아 스스로 해결할 수 있도록 교사 개입을 최소화하 고, 또래 갈등이 유아의 놀이를 심각하게 저해하는 가를 판단 하여 개입하되 유아 개별적으로 갈등상황을 지도하여, 유아들 이 진행하던 놀이가 지속될 수 있도록 돕는다고 할 수 있다. 즉, 유아교사는 높은 주도성을 갖고 유아들의 놀이상황에 참여하 기도 하고 유아들과 친구가 되어 놀이자로 참여하기도 하며 유 아를 이해하기 위해 직접 개입 없이 유아의 일상생활과 놀이 활동을 지켜보기도 하는 등 유아의 경험과 활동의 상황에 따라 활동 참여의 방식을 다양하게 변화시켜야 하는 것이다.

유아의 발달과 학습에 있어서 또래 관계와 또래 놀이 상호 작용이 갖는 중요성과 의미는 더 이상 반복하여 언급할 필요 가 없을 것이다. 그러므로 교사가 유아의 놀이를 포함한 일 상생활 활동에서 적절한 개입이나 참여를 할 수 있는 능력과 교수행동에 자신감을 갖는 것은 중요하다. 교사가 유아의 놀 이가 유아의 성장과 발달에 있어서 중요하며 그 자체로 가치 가 있음을 인식하고 있는 경우 교수활동 및 행동에 실제 놀이 를 더 많이 활용하고 적용하는 경향이 있으므로(Dako-Gyeke, 2008; Proyer, 2011) 유아교사가 일상생활이 놀이가 될 수 있도 록 유아와의 일과 활동에서 다양한 지원자 역할을 수행 하는 것이 또래 놀이 상호작용을 향상시키는 데 효과적일 것이다.

본 연구 결과는 교사-유아의 상호작용은 유아교사의 교수 효능감과 유아의 또래 놀이 상호작용의 하위요인인 놀이단절 의 관계를 매개하였는데, 이러한 결과는 교사교육을 통해 유 아교사가 높은 질의 상호작용을 시도할 수 있도록 지속적인 지원의 기회를 제공하는 것이 필요함을 시사한다. 또한 유아 교사가 유아와의 효율적인 상호작용의 활발한 시도를 유아의 또래 놀이 상호작용으로 이어질 수 있도록 하는 경험이 필요 하다. 특히 그 동안 유아교사는 유아의 놀이를 지도하고 비계 를 설정하여 이끌어주는 상호작용자 역할을 잘 수행해야 하는 것으로 인식되어져 왔으나 놀이중심 교육과정 안에서 진정한 교사의 역할은 함께 배우는 동료도 될 수 있고, 일상생활의 놀 이 매체가 될 수도 있으며 유아들과 놀이친구로 관계 맺는 놀 이대장과 같은 역할을 하는 것이 더욱 중요하다는 것을 확인 할 수 있다. 또한 유아교사의 교육적 신념인 교수효능감을 기 
르고 표현할 수 있도록 하는 기회를 제공하는 것도 유아의 또 래 놀이 상호작용을 향상시킬 수 있는 방안임을 시사한다.

본 연구의 제한점을 바탕으로 후속 연구의 방향을 제안하 면 다음과 같다. 첫째, 본 연구에 사용된 유아교사의 교수효능 감과 교사-유아의 상호작용, 유아의 또래 놀이 상호작용은 모 두 유아교사의 의해 평정된 데이터라는 한계점을 갖는다. 그 러나 교사가 갖는 유아의 행동에 대한 인식이 부모에 비하여 보다 더 평균적이며, 명확하게 인식하고 있다고 보고되고 있 어(Firmin, Proemmel, \& Hwang, 2005), 자료의 객관성과 신뢰 도가 확보된다고 볼 수 있으며 후속 연구에서는 측정방법의 타당성을 높일 수 있는 객관적인 관찰평정을 위한 도구나 기 관의 평가자료 등을 살펴보는 방법도 고려하는 것이 필요하 다. 둘째, 본 연구는 유아의 또래 놀이 상호작용과 관련된 변인 으로 부모와의 관계성은 포함하지 못하여 유아의 또래 놀이 상호작용에 대한 이해에 한계가 있다. 이후 연구에서는 부모 가 가진 양육 효능감이나 만족도 등의 부모와의 관계성 변인 도 함께 고려되어 유아 개인요인과의 인과적 관련성이 검토되 면 또래 놀이 상호작용에 대한 다각적 이해에 한층 더 도움이 될 수 있을 것이다.

이러한 제한점에도 본 연구는 한국아동패널 자료를 이용 함으로써 표본의 모집단의 대표성이 일정 수준 인정된다. 또 한 놀이중심 교육과정이 어린이집 현장에서 그 기능을 수행하 기 위한 방안으로 강화되면서 유아에게 놀이는 생활이라는 관 점을 두고 유아의 또래 놀이 상호작용에 영향을 미치는 변인 으로 유아교사의 교수효능감, 교사-유아 상호작용에 주목하 여 실증적인 그 관계를 탐구해 보고자 하였음에 그 의미를 부 여할 수 있다. 더불어 또래 놀이 상호작용의 세 가지 요인인 놀 이 상호작용, 놀이방해, 놀이단절은 각각의 특성을 지니고 있 으며, 각기 다른 수준에 따라 다양한 유아의 발달영역에 영향 을 미치는 것으로 확인되었으므로(Choo, Xu, \& Haron, 2012; Jung \& Chi, 2006), 교수효능감이 교사-유아 상호작용을 매개 로 하여 또래 놀이 상호작용의 각 특성에 따른 구체적인 영향 력을 밝혔다는 점에서 의미가 있다. 특히 교사-유아 상호작용 의 매개효과를 밝히는 과정에 교수효능감과 유아의 또래 놀이 상호작용을 증진 시킬 수 있는 구체적 교사교육의 방향을 제 시하고 놀이중심 교육과정의 통합적 운영을 위한 교사교육 프 로그램 개발의 기초자료 제공에 기여하였다는 점에서 더욱 그 의의를 갖는다.

\section{Acknowledgements}

This study was supported by the 2019 research grant of Sangmyung University.

\section{Notes}

This article was presented at 2020 Spring Online Conference of Korean Association of Child Studies.

\section{Conflict of Interest}

No potential conflict of interest relevant to this article was reported.

\section{References}

\section{In English}

Bandura, A. (2006). Guide for creating self-efficacy scales. In F. Pajares \& T. Urdan (Eds.), Self-efficacy beliefs of adolescents (Illustraed ed., Vol. 5, pp. 307-337). Charlotte, NC: Information Age Publishing.

Bredekamp, V. S. (1985). The reliability of the instruments and procedures of a national accreditation system for early childhood programs (Unpublished doctoral dissertation). University of Maryland, College Park, MD.

Buhs, E. S., \& Ladd, G. W. (2001). Peer rejection as antecedent of young children's school adjustment: An examination of mediating processes. Developmental Psychology, 37(4), 550560. doi:10.1037/0012-1649.37.4.550

Cheng, S. F. (2000). A teacher's understanding and practices regarding children's play in a Taiwanese kindergarten (Unpublished doctoral dissertation). University of Texas at Austin, Austin, TX.

Choo, M. S., Xu, Y., \& Haron, P. F. (2012). Subtypes of nonsocial play and psychosocial adjustment in Malaysian preschool children. Social Development, 21(2), 294-312. doi:10.1111/ j.1467-9507.2011.00630.x

Dako-Gyeke, M. (2008). Ghanaian preschool and kindergarten teachers' beliefs about children's play (Unpublished doctoral dissertation). Texas Woman's University, Denton, TX.

Dickinson, D. K., Darrow, C. L., \& Tinubu, T. A. (2008). Patterns of teacher-child conversations in Head Start classrooms: 
Implications for an empirically grounded approach to professional development. Early Education and Development, 19(3), 396-429. doi:10.1080/10409280802065403

Downer, J., Sabol, T. J., \& Hamre, B. (2010). Teacher-child interactions in the classroom: Toward a theory of withinand cross-domain links to children's developmental outcomes. Early Education and Development, 1(5), 699723. doi:10.1080/10409289.2010.497453

Fantuzzo, J., Coolahan, K., Mendez, J., McDermott, P., \& SuttonSmith, B. (1998). Contextually-relevant validation of peer play constructs with african-american head start children: Penn Interactive Peer Play Scale. Early Childhood Research Quarterly, 13(3), 411-431. doi:10.1016/S0882006(99)80048-9

Fantuzzo, J., Sutton-Smith, B., Coolahan, K. C., Manz, P.H., Canning, S., \& Debnam, D. (1995). Assessment of preschool play interaction behaviors in young low-income children: Penn Interactive Peer Play Scale. Early Childhood Research Quarterly, 10(1), 105-120. doi:10.1016/08852006(95)90028-4

Firmin, M. W., Proemmel, E., \& Hwang, C. (2005). A comparison of parent and teacher ratings of children's behaviors. Educational Research Quarterly, 29(2), 18-28.

Fumoto, H. (2011). Teacher-child relationship and early childhood practice: Early years. An International Journal of Research and Development, 31(1), 19-30. doi:10.1080/09575146.20 10.535790

Gibson, S., \& Dembo, M. H. (1984). Teacher efficacy: A construct validation. Journal of Educational Psychology, 76(4), 569582. doi:10.1037/0022-0663.76.4.569

Hayes, A. F. (2017). Introduction to mediation, moderation, and conditional process analysis: A regression based approach (2nd ed.). New York: Guilford Press.

Holloway, S. D., \& Reichhart-Erickson, M. (1988). The relationship of day care quality to children's free-play behavior and social problem-solving skills. Early Childhood Research Quarterly, 3(1), 39-53. doi:10.1016/0885-2006(88)90028-2

Leflot, G., Onghena, P., \& Colpin, H. (2010). Teacher-child interactions: Relations with children's self-concept in second grade. Infant and Child Development, 19(4), 385405. doi:10.1002/icd.672

Proyer, R. T. (2011). Being playful and smart? The relations of adult playfulness with psychometric and self-estimated intelligence and academic performance. Learning and Individual Differences, 21(4), 463-467. doi:10.1016/j.lindif.2011.02.003

Ramey, S L., \& Ramey, C T. (2000). Early childhood experiences and developmental competence. In S. Danziger \& J. Waldfogel (Eds.), Securing the future: Investing in children from birth to college (pp. 122-150). New York: Russell Sage Foundation.
Riggs, I. M., \& Enochs, L. G. (1990). Toward the development of an elementary teacher's science teaching efficacy belief instrument. Science Education, 74(6), 625-637. doi:10.1002/ sce. 3730740605

Spodek, B., \& Saracho, O. N. (1990). Preparing early childhood teachers for the twenty-first century: A look to the future. In B. Spodek \& O. N. Saracho (Eds.), Early childhood teacher preparation (Vol. 1, pp. 209-221). New York: Teachers College Press.

Stanton-Chapman, T. L., \& Hadden, D. S. (2011). Encouraging peer interactions in preschool classrooms: The role of the teacher. Young Exceptional Children, 14(1), 17-28. doi:10.1177/1096250610395458

Stipek, D. J., \& Byler, P. (1997). Early childhood education teacher: Do they practice what they preach? Early Childhood Research Quarterly, 12(3), 305-325. doi:10.1016/S08852006(97)90005-3

Trawick-Smith, J., \& Dziurgot, T. (2011). 'Good-fit' teacherchild play interactions and subsequent autonomous play of preschool children. Early Childhood Research Quarterly, 26(1), 110-123. doi:10.1016/j.ecresq.2010.04.005

Tschannen-Moran, M., Hoy, A. W., \& Hoy, W. K. (1998). Teacher efficacy: Its meaning and measure. Review of Educational Research, 68(2), 202-248. doi:10.3102/00346543068002202

Van Hoorn, J., Nourot, P. M., Scales, B., \& Alward, K. R. (2007). Play at the center of the curriculum (4th ed.). London, England: Pearson.

Vitiello, V. E., Booren, L. M., Downer, J. T., \& Williford, A. P. (2012). Variation in children's classroom engagement throughout a day in preschool: Relations to classroom and child factors. Early Childhood Research Quarterly, 27(2), 210-220. doi:10.1016/j.ecresq.2011.08.005

Vygotsky, L. (1978). Mind in society: The development of higher psychological processes. Cambridge, MA: Harvard University.

Wilcox-Herzog, A., \& Ward, S. L. (2004). Measuring teachers' perceive interactions with children: A tool for assessing beliefs and intentions. Early Childhood Research \& Practice. Retrieved from ERIC database. (EJ1084876)

Wing, L. A. (1995). Play is not the work of the child: Young children's perceptions of work and play. Early Childhood Research Quarterly, 10(2), 223-247. doi:10.1016/08852006(95)90005-5

\section{In Korean}

Cho, S.-Y., \& Lee, Y.-J. (2014). A study on the level of implementation and requirements of nuri curriculum by age of 3-5 according to the work experience of preschool teachers and age of preschool children. The Journal of Child Education, 23(3), 425-446. 
Cho, S.-Y., \& Park, E.-H. (2014). The images of play in early childhood educational facilities expressed through young children's drawings. Early Childhood Education Research \& Review, 18(2), 35-57.

Choi, E., \& Kim, E. (2019). The effect of child s peer-play interaction characteristics on academic ability and school readiness. Journal of Learner-Centered Curriculum and Instruction, 19(1), 1333-1353. doi:10.22251/jlcci.2019.19.1.1333

Choi, H. Y., \& Shin, H. Y. (2008). validation of the penn interactive peer play scale for Korean children. Korean Journal of Child Studies, 29(3), 303-318.

Choi, M. S., \& Hwang, Y. S. (2007). The relationship between interactive peer play, teacher-child relation, and peer competence of young children. Journal of Future Early Childhood Education, 14(1), 103-123.

Gadamer, H.-G. (2000). Wahrheit und Methode (G. Lee, Trans.). Paju, Gyeonggido: Moonhakdongne. (Original work published 1960)

Han, E., \& Huh, H. (2016). A study on influences of teacherchild interaction and teacher's efficacy on peer interaction. Korean Journal of Early Childhood Education, 36(2), 53-70. doi:10.18023/kjece.2016.36.2.003

Hong, Y., Kim, K., Kang, K., \& Kim, S.-J. (2007). Effective ways to administer the full-day kindergarten program. Korean Journal of Early Childhood Education, 27(5). 335-355. doi:10.18023/kjece.2007.27.5.015

Hwang, J.-G. (2017). Relationship among child-care teacher's happiness, self-efficacy, and teacher-young children interaction. Journal of Early Childhood Education \& Educare Welfare, 21(3), 7-25. doi:10.22590/ecee.2017.21.3.7

Jeon, G. I., \& Yi, S. H. (2013). Examining children's peerrelationship strategies of free play in a child-care center. Journal of Korean Child Care and Education, 9(5), 407-436. doi:10.14698/jkcce.2013.9.5.407

Jung, D.-H., \& Chi, S.-A. (2006). A study of the relationships among children's peer interactions, child-teacher relationships, multiple intelligences, and elementary school adjustment. Korean Journal of Early Childhood Education, 26(3), 201-221.

Kim, K., \& Kim, J. A. (2007). A comparison of the management conditions and teacher's recognition of child care center and kindergarten of full-day programs. Journal of Young Child Studies, 10, 55-75.

Kim, M. J. (2013). The relationship between teacher-child relationship perceived by teacher and social competence of young children. Korean Journal of Early Childhood Education, 15(1), 137-163.

Kim, M. S., Hwang, S. Y., \& Oh, J. Y. (2014). Effects of teacher's job-satisfaction and teaching efficacy on children's emotional competences, personality character and social competences. The Journal of Eco Early Childhood Education
\& Care, 13(3), 53-80.

Kim, S. L., \& Park, C. H. (2015). Effects of young children's temperament, teacher efficacy, and teacher-child interactions on peer play interactions. Journal of Korean Child Care and Education, 11(6), 37-58. doi:10.14698/jkcce.2015.11.037

Kim, Y. H., \& Kim, Y. E. (2008). An analysis of the factorial validity of bandura's teacher self-efficacy scale. Journal of Early Childhood Education, 28(2), 169-191. doi:10.18023/ kjece.2008.28.2.008

Kwon, H. J. (2012). The mediating effect of teachers' positive beliefs about children's play on the relationship between playfulness in teachers and teaching efficacy on children's play. Korean Journal of Child Studies, 33(6), 133-147. doi:10.5723/KJCS.2012.33.6.133

Kwon, H.-K. (2009). A study of young children's interactive peer play with relationship of children's self-efficacy and social competence. Early Childhood Education Research \& Review, 13(6), 391-410.

Lee, J., Lee, S., \& Lee, J. Y. (2019). A study on the relationship between children's happiness, teacher-children relationships, peer interactions according to gender. Korean Joural of Children's Media, 18(4), 247-269. doi:10.21183/ kjcm.2019.12.18.4.247

Lee, S.-K., \& Kim, H.-W. (2016). The structural relationships among classroom environment, teacher-child interaction, children's cognitive ability and peer interaction. Journal of Learner-Centered Curriculum and Instruction, 16(10), 925945. doi:10.22251/jlcci.2016.16.10.925

Lim, B., Kwon, H., Kim, S., Sing, W., Shin, Y., Shin, E.,...Choi, Y. (2019). Gaejeing nurikwajeong haeseolseo [개정 누리과정 해설서]. Sejong, Chungcheongnamdo: Korea: Ministry of Education, \& Ministry of Health and Welfare.

Min, M. (2019). The effects of teacher-child interaction, peer play interaction, and social competence preschoolers on the school readiness: Multigroup analysis across gender. Journal of Future Early Childhood Education, 26(3), 1-22. doi:10.22155/JFECE.26.3.1.22

Moon, Y. K., \& Choi, S. N. (2015). Teachers' teaching efficacy on preschoolers' peer interaction: Focusing on the mediating effect of teachers-child interaction. Korean Journal of Child Education and Care, 15(2), 1-20.

Panel Study on Korean Children. (2014). Panel study of Korean children 7 rd survey [Data file and codebook]. Retrieved from https://panel.kicce.re.kr/panel/module/rawDataManage/ index.do

Park, C.-O., \& Hwang, S. (2012). A study of the change for the nonsocial child's social behavior in the process of forming the peer relationships. Early Childhood Education Research \& Review, 16(1), 325-349.

Seo, S., \& Park, J. (2016). The effect of teacher`s teaching-efficacy 
and classroom environment on peer-play interaction: Mediation effect of teacher-child interaction. Family and Environment Research, 54(3), 293-305. doi:10.6115/ fer.2016.023

Shim, S. Y., \& Lim, S. A. (2017). The relationship among teacher efficacy, teacher-child interaction, and peer play interaction: Mediation effect of child temperament. Korean Journal of Early Childhood Education, 37(4), 353-369. doi:10.18023/ kjece.2017.37.4.014

Shin, E. (2000). The effects of teacher's efficacy beliefs about play on teacher-child interaction and children's play. Journal of Early Childhood Education, 20(1), 27-42.

Shin, E., Kwon, M. K., \& Jeong, H. B. (2010). The relationships between social skills, peer play interactions and social play behaviors. Journal of Future Early Childhood Education, 17(4), 183-209.

Shin, E., \& Park, H. (2006). Effects of teacher education about pretend play on teachers' efficacy of play, teachers' intervention, and levels of children's social pretend play. Korean Journal of Early Childhood Education, 26(6), 287-310.

Song, M., Ryu, S., \& Lee, B. (2017). Mediating effect of teacherchild interaction on the relationship between teachers' happiness and child-peer play interaction. Korean Journal of Early Childhood Education, 37(4), 273-295. doi:10.18023/ kjece.2017.37.4.011

Suh, H. J., \& Lee, H. A. (2011). Preschool teacher's experience on preschooler-initiated play time. Early Childhood Education Research \& Review, 15(6), 119-144.

Yi, J. J., \& Choi, N. Y. (2013). The relationship among teacher's play beliefs, play teaching efficacy and teacher-children interaction. Korean Journal of Child Education and Care, 13(3), 183-203.

Yoo, M.-H., \& Lee K.-N. (2019). The structural relationships among teacher-child interaction, young children's academic skills, peer play interaction and school readiness. Journal of Future Early Childhood Education, 26(2), 1-23. doi:10.22155/ JFECE.26.2.1.23

\section{ORCID}

Su Mi Lim

http://orcid.org/0000-0001-7078-235X

Hae Shin Hwang http://orcid.org/0000-0002-2905-354X

Received August 31, 2020

Revision received October 25, 2020

Accepted December 4, 2020 